\title{
EVOLUÇÃO DA PRODUÇÃO DE CARNE SUÍNA NO BRASIL: UMA ANÁLISE ESTRUTURAL-DIFERENCIAL ${ }^{1}$
}

\author{
Gislene Zinato Rodrigues ${ }^{2}$ \\ Marília F. Maciel Gomes ${ }^{3}$ \\ Denis Antônio da Cunha ${ }^{4}$ \\ Vladimir Faria dos Santos ${ }^{5}$
}

\begin{abstract}
Resumo: Objetivou-se, neste trabalho, analisar as participações dos principais estados produtores do Brasil (Minas Gerais, São Paulo, Paraná, Santa Catarina, Rio Grande do Sul, Mato Grosso do Sul, Mato Grosso e Goiás) na produção nacional de carne suína inspecionada e total, no período de 2000 a 2006. A análise considerou a evolução da produção, em termos do efeito regional (ou locacional), e também de indicadores da evolução técnica da atividade. O referencial teórico usado foi a teoria da modernização da agricultura, mais especificamente o modelo de inovação induzida. O método de análise foi o Modelo Estrutural-Diferencial. Os resultados obtidos permitem concluir que a produção suinícola brasileira apresentou importantes transformações. Embora a produção total de carne suína tenha apresentado crescimento significativo, a produção inspecionada mostrou dinamismo superior. Pode-se falar em um deslocamento espacial da produção, em busca de proximidades com áreas fornecedoras de matérias-primas. $\mathrm{O}$ resultado é uma dinâmica de modernização da produção nas regiões de fronteira agrícola, tendência que já havia sido verificada na pecuária bovina.
\end{abstract}

Palavras-chave: fator locacional, fator tecnológico, Modelo Shift-Share, carne suína.

Recebido em: 27/10/08; Aceito em 25/01/2009.

2 Bacharela em Gestão de Agronegócio, Departamento de Economia Rural, Universidade Federal de Viçosa . Bolsista PIBIC/CNPq, gzinato@yahoo.com.br

3 Professora Associada II, Departamento de Economia Rural, Universidade Federal de Viçosa, mfmgomes@ufv.br

4 Doutorando em Economia Aplicada, Departamento de Economia Rural, Universidade Federal de Viçosa, denisufv@gmail.com

5 Doutorando em Economia Aplicada, Departamento de Economia Rural, Universidade Federal de Viçosa, vladi_fs@yahoo.com.br 


\section{Introdução}

O agronegócio tem grande importância para a economia nacional, pois apresenta amplo potencial de geração de empregos, renda e divisas. O setor tem ampliado sua produção continuamente, promovendo o desenvolvimento do interior do país e incrementando as exportações. $\mathrm{O}$ agronegócio foi um dos grandes responsáveis pela retomada do crescimento econômico e, em razão da abertura comercial intensificada a partir do início do ano de 1990, vem procurando especializar-se, cada vez mais, em tecnologia, com vistas em aprimorar suas atividades e tornar o setor competitivo e com destaque no mercado internacional (GOMES, 2002; RODRIGUES, 2006).

Dentre as diferentes cadeias produtivas integrantes do sistema agroindustrial brasileiro, a de suínos vem se destacando pelo forte dinamismo, em razão das mudanças nas características dos produtos, na inserção no mercado internacional; pelos ganhos tecnológicos; e pelas sensíveis alterações da escala de operação. A cadeia suinícola brasileira também se destaca por apresentar grande articulação entre os diferentes agentes que a compõem, bem como pelo volume de investimentos injetados na atividade (GOMES, 2002). Nessa atividade ocorre grande variedade de formas organizacionais, que vão desde pequenos produtores independentes, com fornecimento caseiro e consumo local, até infraestruturas agrícolas com integração vertical, que vendem em bases nacionais e internacionais.

A atividade suinícola brasileira vem passando por profundas transformações. Com a abertura comercial no início de 1990 e com a desvalorização cambial em 1999, o Brasil conseguiu aumentar sua produção e ampliar suas exportações no mercado internacional, passando a configurar, em 2006, como quarto maior produtor e exportador mundial (FIALHO, 2006). No entanto, essa atividade vem enfrentando problemas de origem sanitária, devido ao surgimento de algumas enfermidades, como a doença de Aujezky, a Encefalopatia Espongiforme Bovina ("mal da 
Gislene Zinato Rodrigues, Marília F. Maciel Gomes,

Denis Antônio da Cunha \& Vladimir Faria dos Santos

vaca louca"), a gripe aviária e a febre aftosa. Em paralelo, percebe-se no mercado uma mudança no comportamento dos consumidores, que passaram a observar as condições de segurança alimentar e buscar produtos mais saudáveis.

Dada a crescente preocupação com a questão sanitária e dada a imposição de barreiras comerciais às exportações de carne suína, temse verificado a intensificação de medidas que visam melhorar o perfil sanitário dos suínos. Como resultado, a produção brasileira de carne inspecionada vem apresentando taxas anuais de crescimento bastante elevadas. No período de 2000 a 2006, a produção total aumentou cerca de $19 \%$ (2,9\% ao ano, conforme a taxa geométrica de crescimento), e os estados que apresentaram crescimento mais significativo foram Mato Grosso e Minas Gerais, com 88\% e 43\%, respectivamente. Em relação à produção inspecionada, o crescimento foi consideravelmente maior, aproximadamente $71 \%$ (9,3\% ao ano), e Goiás e Mato Grosso destacaram-se pelo respectivo aumento de $1640 \%$ e $262 \%{ }^{6}$.

Deve-se considerar, no entanto, que esse incremento expressivo na produção de carne suína inspecionada não ocorreu de forma homogênea em todas as regiões brasileiras. Nos últimos cinco anos, a região Sul ampliou sua participação no rebanho em $2,13 \%$, embora sua participação nos abates inspecionados tenha caído 7,40\%. As regiões Norte e Nordeste tiveram redução relativa nos seus rebanhos suínos $(4,01 \%)$ e pequeno aumento de sua participação nos abates inspecionados $(0,04 \%)$. O Sudeste sofreu redução de $0,58 \%$ na dimensão do rebanho e aumentou em $2,66 \%$ sua participação nos abates inspecionados, enquanto o CentroOeste teve tanto ampliação na participação no rebanho quanto nos abates inspecionados, $2,46 \%$ e 4,80\%, respectivamente (IBGE, 2007).

Mato Grosso e Goiás têm se destacado tanto no que se refere à participação na produção total, quanto na produção inspecionada. Segundo Andrade (2005), esse é um resultado da proximidade da produção ao

6 As Tabelas A1 e A2, do Anexo, contêm índices da quantidade total produzida de carne suína e carne suína inspecionada para o Brasil e os principais estados produtores 
complexo de grãos, o que é visto como fator positivo para os investimentos de empresas nacionais e multinacionais na região. Consequentemente, esses estados têm atraído agroindústrias com produção tecnificada e utilização de tecnologias mais avançadas. Deve-se considerar também a atuação eficiente dos agentes de fiscalização, o que acarreta melhorias nas condições sanitárias do rebanho.

Considerando a importância da produção de carne suína inspecionada para atender aos padrões internacionais de segurança alimentar e o desejo dos consumidores em adquirir um alimento mais saudável, torna-se relevante estudar o crescimento da produção, em termos do efeito regional (ou locacional), e também de indicadores da evolução técnica da atividade, como os efeitos da dimensão do rebanho, do peso médio da carcaça e da taxa de desfrute. Em relação ao fator locacional, que recebe tratamento especial neste estudo, verifica-se nova geografia do setor, já que se constata um novo direcionamento da produção para regiões de fronteira, dada a proximidade desta com áreas fornecedoras de matérias-primas a baixo custo, especialmente milho e soja, que são os principais insumos na produção da ração.

Dessa forma, neste estudo objetivou-se analisar as participações relativas dos principais estados produtores de suínos do Brasil (Minas Gerais, São Paulo, Paraná, Santa Catarina, Rio Grande do Sul, Mato Grosso do Sul, Mato Grosso e Goiás) tanto na produção total desse tipo de carne quanto na produção inspecionada, no período de 2000 a 2006. Buscou-se, ainda, verificar de que forma o fator locacional tem importância relativa significativa tanto para os dados em nível nacional quanto para os estados em análise.

Além desta introdução, o artigo está dividido em outras cinco seções. Na segunda são apresentadas algumas notas sobre a teoria da modernização; na terceira, a metodologia, assentada numa adaptação do Modelo Estrutural-Diferencial; na quarta, a fonte de dados; na quinta, os resultados e discussões; e, na sexta, as conclusões que finalizam a presente pesquisa. 
Gislene Zinato Rodrigues, Marília F. Maciel Gomes,

Denis Antônio da Cunha \& Vladimir Faria dos Santos

\section{Teoria da modernização}

O modelo teórico que sustenta este trabalho é a teoria da modernização, mais especificamente a teoria da inovação induzida.

A modernização é um processo de mudança econômica, social e política, por meio do qual as estruturas produtivas tradicionais são substituídas por formas de produção mais desenvolvidas, e os fatores de produção são realocados de tal forma que sua produtividade seja aumentada.

Por meio da modernização da agricultura, os produtores têm condições de romper as restrições impostas pela natureza e melhorar a forma com que alguns fatores são utilizados, aumentando sua produtividade e, consequentemente, a produção. Esse aumento da produtividade pode ser atingido por meio da conservação artificial e fertilização do solo, da mecanização da lavoura, da utilização de sementes selecionadas, dentre outros recursos.

Para Schuh (1971), alguns fatores são fundamentais para o progresso da agricultura. Esses fatores, que podem ser entendidos como catalisadores da modernização, são a maior consideração do setor pela ciência e tecnologia, o maior número de técnicos bem treinados, a infra-estrutura de pesquisa, o crescente setor industrial e a riqueza em recursos naturais. Ao contrário desses, também existem fatores que podem obstruir o processo, tais como falta de tecnologia de produção, baixa taxa de investimento, falta de integração entre ensino, pesquisa e extensão, mercado de insumos inadequado, altos preços relativos dos insumos modernos, políticas ineficientes voltados ao setor, e a inflação.

No ponto de vista de Hayami e Ruttan (1988), o caminho eficiente para a modernização e para o crescimento do produto será determinado, em grande parte, pela dotação relativa de fatores. Segundo esses autores, são muitos os caminhos que um país pode percorrer para alcançar o desenvolvimento tecnológico, ou até mesmo para a mudança tecnológica. 
Outro aspecto fundamental que deve ser levantado é o papel atribuído à tecnologia de produção, cuja função é facilitar a substituição de um recurso por outro, a fim de aliviar a restrição imposta pela inelasticidade na oferta dos fatores e, consequentemente, aumentar o produto (HAYAMI; RUTTAN, 1988).

Hayami e Ruttan (1988) também argumentam que, para se obter mudança na eficiência das técnicas utilizadas, é preciso desenvolver a capacidade local de pesquisa, isto é, a tecnologia de produção deve ser desenvolvida dentro da região na qual será aplicada e estar de acordo com as condições ambientais e com a dotação de recursos especifica do local. Além disso, é necessário desenvolver a capacidade industrial para produção de insumos modernos, tais como tratores e fertilizantes, que substituam os de oferta inelástica. Outra opção é a importação desses insumos de países onde o custo de produção é menor, uma vez que a eficiência produtiva e econômica das inovações biológicas e mecânicas depende de suprimento adequado e a baixos custos.

No trabalho desenvolvido por Daguer (1984) também são encontradas características relativas à modernização da agricultura. $\mathrm{O}$ motivo que leva algumas regiões a apresentarem retardos no processo de modernização em relação a outras, de acordo com a referida autora, pode ser explicado pela "teoria das barreiras", de Schuh (1975). Segundo esta teoria, o atraso tecnológico da agricultura, em algumas regiões, devese à abundância dos fatores tradicionais (trabalho e recursos naturais) em relação aos insumos modernos. Não obstante, outros fatores também podem ser incluídos para justificar os baixos índices de tecnificação e produtividade agrícola. Entre esses índices incluem-se o baixo nível de qualificação do trabalhador e do proprietário, o baixo nível de capitalização dos agricultores, o reduzido estoque de conhecimento tecnológico à disposição do empresário rural, a elevada incidência de minifúndio e latifúndios e, finalmente, a ineficiência técnica de algumas regiões agrícolas. 


\subsection{Inovação Induzida}

O modelo supõe que, dadas as alternativas tecnológicas disponíveis, a promoção do desenvolvimento rural depende da habilidade em eleger e pôr em prática aquelas que facilitem a substituição de fatores de produção relativamente escassos e, portanto, mais caros por outros relativamente abundantes. Essas tecnologias devem ser empregadas quando a terra tiver custo elevado, pois permitem que esta seja explorada de forma mais intensa e racional.

As bases teóricas e empíricas desse modelo encontram-se em Hayami e Ruttan (1988). Trata-se de contribuição das mais importantes para compreender a direção tomada pelas mudanças tecnológicas, a dinâmica do processo de modernização e algumas dificuldades que precisam ser superadas para promovê-lo ${ }^{7}$.

Por essa razão, esses autores enfatizam a necessidade de os centros de pesquisa públicos e privados despenderem esforços para gerar inovações tecnológicas que permitam substituir os fatores de produção relativamente escassos por outros de menor custo e superar as limitações impostas ao desenvolvimento rural.

No caso dos centros de pesquisa públicos, cujas atividades não visam lucros, a geração de inovações tecnológicas depende do processo de interação entre pesquisadores, produtores, extensionistas rurais e empresas privadas.

Em outros casos, o processo de integração decorre de pressões dos produtores, da necessidade de tornar a agricultura mais competitiva em nível regional, nacional e internacional ou do desejo dos pesquisadores

As questões da mudança tecnológica e dinâmica do processo de modernização na agricultura têm sido tema de muitos estudos. A orientação desta pesquisa convergiu para a linha desenvolvida por Hayami e Ruttan (1988). Não obstante, sobre o assunto supracitado existe uma discussão teórica ampla, sendo isto observado, por exemplo, em: Salles Filho e Silveira (1990), Silva (1992), Salles Filho (1993), Shikida e Lopes (1997), dentre outros. 
de se tornarem úteis à sociedade, ou de obterem ganhos materiais, prestígio, reconhecimento e outras formas de recompensa.

Hayami e Ruttan (1988) assinalam que o mecanismo de indução prevista pelo modelo não funciona de modo automático. O primeiro pré-requisito para isso é que o sistema de preços reflita, sem distorções, as reais condições de oferta e demanda dos diferentes bens, serviços e fatores de produção. O segundo é que os produtores sejam suficientemente organizados e os centros de pesquisa adequadamente localizados e familiarizados com os problemas rurais, o que facilita o processo de interação.

Quanto às atividades de pesquisa, especificamente, o papel do governo será indispensável sempre que as inovações mais adequadas à realidade rural forem de natureza biológica.

De fato, se a concentração geográfica propiciasse melhor organização dos produtores e dos mercados e facilitasse a formação de grupos de interesse e pressão em torno de problemas comuns, tais problemas seriam mais localizados, melhor percebidos e mais facilmente transmitidos aos pesquisadores, o que possibilitaria sua mais rápida solução. Desse modo, a seleção de prioridades representa um passo decisivo para que os recursos e esforços - cronicamente escassos nesses países - sejam aplicados com maior eficiência e em sintonia com as reais necessidades.

\section{Metodologia}

Utilizou-se neste trabalho uma adaptação do Modelo EstruturalDiferencial, também conhecido como Modelo Shift-Share. Este é um método que permite medir as fontes de crescimento de agregados econômicos com enfoque regional (CURTIS, 1972). No Brasil, o modelo Shift-Share tem sido utilizado para avaliar o desempenho dos setores agrícola e pecuário. 
Segundo Haddad e Andrade (1989), o modelo Shift-Share procura descrever o crescimento econômico de uma região, em relação a sua estrutura produtiva, ou seja, decompor a variação observada na produção entre o período base " 0 " e o período final " $t$ ", a fim de encontrar a diferença $\left(Q_{t}-Q_{0}\right)$ entre os fatores que seriam os responsáveis pelo crescimento (ou queda) da produção. Desse modo, este modelo não é uma teoria explicativa do crescimento regional, mas um método de análise para identificar os componentes de crescimento.

Diferentes autores brasileiros utilizaram esse método em suas análises, dentre eles, Moreira (1996), Santos et al. (2000), Igreja et al. (2006) e Oliveira et al. (2008).

A variação na produção de carne suína nas regiões brasileiras, objeto de análise deste estudo, é decomposta nos efeitos: dimensão do rebanho, peso médio da carcaça, taxa de desfrute e localização geográfica. $\mathrm{O}$ efeito localização geográfica permite determinar, por exemplo, o fator locacional no crescimento da produção da carne suína inspecionada, quando sua expressão na produção total diminui, revelando problemas relacionados com serviços de vigilância e defesa sanitária, que levam à menor capacidade de competitividade da cadeia produtiva. Em contraposição, tem-se o fator tecnológico (medido pela produção simulada pelos efeitos peso médio da carcaça e taxa de desfrute), que pode acentuar ou atenuar a perda de capacidade competitiva de determinada região/estado.

A metodologia de análise permite mensurar efeitos relevantes para o crescimento da produção da carne suína. O caráter diferencial é dado por diferenças que se obtêm na produção, quando ela é simulada com os efeitos considerados.

Para obter os referidos efeitos, parte-se de cinco identidades, somatórias dos estados $i$, tal como estão definidas a seguir, de (1) a (5).

$Q_{0}=\sum \delta_{i o} \cdot \alpha_{i o} \cdot G_{o} \cdot W_{i o}$ 
$Q_{t}=\sum \delta_{i t} \cdot \alpha_{i t} \cdot G_{t} \cdot W_{i t}$

$Q_{t}^{R}=\sum \delta_{i 0} \cdot \alpha_{i 0} \cdot G_{t} \cdot W_{i 0}$

$Q_{t}^{w}=\sum \delta_{i 0} \cdot \alpha_{i o} \cdot G_{t} \cdot W_{i t}$

$Q_{t}^{D}=\sum \delta_{i t} \cdot \alpha_{i 0} \cdot G_{t} \cdot W_{i t}$

em que $\alpha_{i 0}$ é participação percentual do estado i no rebanho suíno do Brasil; $\delta_{0 t}$, taxa de desfrute do estado i; $G_{0}$ e $G_{t}$, dimensão do rebanho suíno, Brasil, período inicial (0) e período final(t); $W_{i 0}$ e $W_{i t}$, peso médio da carcaça, estado i, período inicial (0) e período final (t).

A identidade (1) afere a quantidade produzida no período inicial (0); a identidade (2), a quantidade produzida no período final (t); a (3), a produção de carne suína em uma situação hipotética, em que se considera que somente a dimensão do rebanho variou entre um período inicial (0) e um período final (t); e a (4) expressa a produção da carne suína a partir de uma situação hipotética, em que, além da dimensão do rebanho, também o peso médio da carcaça variou entre $(0)$ e $(\mathrm{t})$.

Finalmente, a identidade (5) expressa a produção da carne suína a partir de uma situação hipotética, em que, além das variáveis mencionadas anteriormente, a taxa de desfrute também variou entre $(0)$ e $(t)$.

Pode-se demonstrar que uma seqüência de diferenças compõe a variação total da produção entre $(0)$ e $(t)$, a saber:

$$
\begin{aligned}
& {[(3)-(1)]+[(4)-(3)]+[(5)-(4)]+[(2)-(5)]=[(2)-(1)]} \\
& \begin{array}{llll}
\text { a) } & \text { (b) } & \text { (c) } & \text { (d) }
\end{array}
\end{aligned}
$$

em que (a) mede a contribuição da dimensão do rebanho para a variação total na produção de carne suína, entre os períodos inicial (0) e final (t); 
Gislene Zinato Rodrigues, Marília F. Maciel Gomes,

Denis Antônio da Cunha \& Vladimir Faria dos Santos

(b) identifica a contribuição do peso médio da carcaça; (c) afere a contribuição da taxa de desfrute; (d) expressa a contribuição da localização geográfica; e (e) diferencial.

Deve-se lembrar que, neste estudo, o Modelo Estrutural-Diferencial é utilizado em toda a série de dados estatísticos, sendo, portanto, o período (0) correspondente a determinado ano e o período ( $t$ ), ao ano subseqüente. Os diferenciais obtidos para cada efeito são somados sucessivamente ao ano-base da série e, dessa forma, são obtidas simulações de séries históricas para cada um dos efeitos obtidos.

\section{Fonte de dados}

Os dados utilizados neste trabalho foram originários de duas fontes. A primeira foi do Instituto Brasileiro de Geografia e Estatística (IBGE, 2007), por meio da Pesquisa Trimestral de Abate de Animais e da Pesquisa Pecuária Municipal. Da pesquisa trimestral de Abate de animais foram obtidas as variáveis número total de animais enviados para abate (Estado $i-N_{i}$ ), peso total dos animais enviados para abate (Estado $\mathrm{i}-W_{i}$ ) e dimensão total do rebanho $\left(G_{i}\right)$. Já da Pesquisa Pecuária Municipal foram obtidas as estatísticas referentes à dimensão do rebanho, que, relacionada com as estatísticas de envio para o abate, permitiram obter a taxa de desfrute $(\mathrm{Ni} / \mathrm{Gi})$.

A segunda fonte de dados foi o Anuário da Pecuária (ANUALPEC, 2007) e Abipecs, Abcs e Embrapa (2007), dos quais foram utilizados os dados referentes ao número total de abates, estimativas do rebanho e quantidades produzidas totais, englobando carnes inspecionadas e não-inspecionadas.

Os dados, de periodicidade anual, foram coletados para o Brasil e também para os estados de Minas Gerais, São Paulo, Santa Catarina, Paraná, Rio Grande do Sul, Goiás, Mato Grosso e Mato Grosso do Sul, no período de 2000 a 2006. 


\section{Resultados e discussão}

Primeiramente, são apresentados os índices da produção nacional de carne suína total e inspecionada, respectivamente, obtidos do Modelo Estrutural - Diferencial, para o cenário nacional (Tabelas 1 e 2) $)^{8}$.

Tabela 1 - Índices da produção total de suínos (2000: 100), Brasil, 2000 a 2006

\begin{tabular}{cccccc}
\hline Ano & $E D R^{1}$ & $E^{2} M^{2}$ & ETD $^{3}$ & ELG $^{4}$ & Produção \\
\hline 2000 & 100,00 & 100,00 & 100,00 & 100,00 & 100,00 \\
2001 & 97,77 & 100,67 & 110,01 & 99,99 & 102,56 \\
2002 & 95,20 & 101,49 & 123,91 & 100,03 & 105,19 \\
2003 & 88,87 & 102,75 & 130,72 & 100,38 & 108,82 \\
2004 & 85,59 & 103,84 & 131,32 & 99,91 & 113,29 \\
2005 & 88,12 & 104,48 & 133,59 & 101,48 & 116,64 \\
2006 & 93,71 & 104,62 & 133,81 & 101,88 & 118,97 \\
\hline
\end{tabular}

${ }^{1}$ Efeito dimensão do rebanho; ${ }^{2}$ Efeito peso médio das carcaças; ${ }^{3}$ Efeito taxa de desfrute; ${ }^{4}$ Efeito localização geográfica.

Fonte: Dados da pesquisa.

8 As simulações que geraram os índices apresentados nas Tabelas 1 e 2 encontram-se no Anexo, Tabelas 3A e 4A. 
Gislene Zinato Rodrigues, Marília F. Maciel Gomes,

Denis Antônio da Cunha \& Vladimir Faria dos Santos

Tabela 2 - Índices da produção inspecionada de suínos (2000: 100), Brasil, 2000 a 2006

\begin{tabular}{|c|c|c|c|c|c|}
\hline Ano & $E D R^{I}$ & $E P M^{2}$ & $E T D^{3}$ & $E L G^{4}$ & Produção \\
\hline 2000 & 100,00 & 100,00 & 100,00 & 100,00 & 100,00 \\
\hline 2001 & 103,22 & 102,56 & 110,16 & 101,18 & 117,54 \\
\hline 2002 & 100,81 & 103,20 & 133,21 & 101,79 & 139,64 \\
\hline 2003 & 102,46 & 103,75 & 133,31 & 102,83 & 142,33 \\
\hline 2004 & 105,83 & 105,93 & 122,94 & 104,43 & 138,65 \\
\hline 2005 & 109,87 & 115,37 & 128,82 & 106,72 & 160,10 \\
\hline 2006 & 111,04 & 114,85 & 140,49 & 107,04 & 170,74 \\
\hline
\end{tabular}

${ }^{1}$ Efeito dimensão do rebanho; ${ }^{2}$ Efeito peso médio das carcaças; ${ }^{3}$ Efeito taxa de desfrute; ${ }^{4}$ Efeito localização geográfica.

Fonte: Dados da pesquisa.

Ao analisar comparativamente os índices apresentados nas Tabelas $1 \mathrm{e}$ 2, verifica-se predominância do efeito taxa de desfrute, que se sobrepôs aos demais efeitos tanto na produção inspecionada quanto na produção total. Esse resultado reflete melhoria na evolução técnica da atividade. Observa-se um crescimento maior de todos os efeitos sobre a produção inspecionada em relação à produção total. Aspecto importante, que justifica essa tendência, está associado a um programa de fiscalização sanitária mais eficiente (na produção, abate, transporte e comercialização) e investimentos em infra-estrutura (pessoal técnico, vacinação, pesquisas, rastreabilidade).

Com relação ao efeito localização geográfica, houve acréscimo de pouco mais de $1 \%$ na produção total e de $7 \%$ na inspecionada. A partir desse resultado, pode-se inferir que aspectos locacionais, como matéria-prima, mão-de-obra, infra-estrutura, incentivos fiscais e questão ambiental, podem ter influenciado diretamente o crescimento da produção de carne suína inspecionada do Brasil. Além disso, de modo similar ao que foi apontado por Igreja et al. (2006), o fato de o efeito localização geográfica ser maior na produção inspecionada pode refletir um maior encadeamento entre a suinocultura e as atividades da indústria frigorífica e também do complexo agroindustrial de abate. 
A relação percentual entre os dados da simulação da produção inspecionada e os da produção total é apresentada na Tabela $3^{9}$.

Tabela 3 - Participação percentual da produção inspecionada na produção total de suínos, Brasil, 2000 a 2006

\begin{tabular}{lllllc}
\hline Ano & EDR $^{1}$ & EPM $^{2}$ & ETD $^{3}$ & ELG $^{4}$ & Produção \\
\hline 2000 & 57,61 & 57,61 & 57,61 & 57,61 & 57,61 \\
2001 & 60,82 & 58,69 & 57,69 & 58,30 & 66,02 \\
2002 & 61,01 & 58,58 & 61,94 & 58,63 & 76,48 \\
2003 & 66,42 & 58,18 & 58,75 & 59,02 & 75,36 \\
2004 & 71,24 & 58,77 & 53,94 & 60,22 & 70,51 \\
2005 & 71,83 & 63,62 & 55,55 & 60,59 & 79,08 \\
2006 & 68,27 & 63,25 & 60,49 & 60,53 & 82,68 \\
\hline
\end{tabular}

${ }^{1}$ Efeito dimensão do rebanho; ${ }^{2}$ Efeito peso médio das carcaças; ${ }^{3}$ Efeito taxa de desfrute; ${ }^{4}$ Efeito localização geográfica.

Fonte: Dados da pesquisa.

Nota-se que houve convergência dos dados em relação à produção nacional em todos os efeitos, o que pode ser explicado pelo rigor sanitário e pela maior eficiência na coordenação entre os agentes econômicos envolvidos na cadeia produtiva. Esse é um indicador de maior qualidade na suinocultura nacional, já que a produção inspecionada tende a prevalecer.

A maior convergência foi observada na simulação da dimensão do rebanho, ao passo que a taxa de desfrute foi a variável que apresentou menor aproximação entre os dados de produção inspecionada e produção total. Para Igreja et al. (2006), esse resultado está de acordo com uma tendência recente, segundo a qual aumentos no plantel exercem maior impacto no abate inspecionado, uma vez que se trata de um processo acompanhado de melhorias genéticas e de manejo, além de intensificação das relações técnicas com a indústria.

Os dados apresentados na Tabela 3 foram obtidos pela divisão da simulação da carne suína inspecionada (Tabela 4A) pela simulação da produção total (Tabela 3A). 
No que se refere ao efeito localização geográfica, verifica-se que este apresentou reduzida aproximação entre os dados de produção inspecionada e produção total, porém a sua convergência foi maior do que a obtida pelo efeito taxa de desfrute e inferior à dos efeitos dimensão do rebanho e peso médio.

Constata-se que a quantidade produzida sob inspeção tendeu rapidamente para os dados da produção total, já que o percentual cresceu de 57,61\%, em 2000, para 82,68\%, em 2006. Um dos fatores determinantes desse resultado é a utilização de tecnologias mais avançadas que levam a melhorias nas condições sanitárias do rebanho.

Após considerar a evolução dos indicadores obtidos pelo Modelo Estrutural - Diferencial para o cenário nacional, apresenta-se, a seguir, uma análise específica do Efeito Localização Geográfica (ELG) para o Brasil e seus principais estados produtores. As Tabelas 4 e 5 contêm os índices obtidos a partir da simulação com o efeito localização para a produção total e inspecionada, respectivamente.

Tabela 4 - Índices da produção total a partir de simulação com o efeito localização geográfica (ELG), 2000 a 2006

\begin{tabular}{cccccccccc}
\hline & Brasil & MG & SP & PR & SC & RS & MS & MT & GO \\
\hline $\mathbf{2 0 0 0}$ & 100,00 & 100,00 & 100,00 & 100,00 & 100,00 & 100,00 & 100,00 & 100,00 & 100,00 \\
$\mathbf{2 0 0 1}$ & 99,99 & 96,54 & 99,93 & 99,36 & 99,82 & 101,53 & 103,89 & 100,64 & 102,78 \\
$\mathbf{2 0 0 2}$ & 100,03 & 92,30 & 99,76 & 98,61 & 99,69 & 103,42 & 108,41 & 101,56 & 107,33 \\
$\mathbf{2 0 0 3}$ & 100,38 & 75,24 & 97,91 & 100,36 & 101,11 & 110,02 & 116,13 & 104,38 & 118,20 \\
$\mathbf{2 0 0 4}$ & 99,91 & 75,32 & 98,66 & 95,88 & 99,25 & 108,96 & 119,92 & 108,03 & 126,21 \\
$\mathbf{2 0 0 5}$ & 101,48 & 83,87 & 96,50 & 95,06 & 103,29 & 113,62 & 116,28 & 110,93 & 130,21 \\
$\mathbf{2 0 0 6}$ & 101,88 & 93,21 & 93,74 & 92,39 & 109,52 & 110,98 & 103,22 & 107,53 & 127,39 \\
\hline
\end{tabular}

Fonte: Dados da pesquisa. 
Tabela 5 - Índices de produção inspecionada a partir de simulação com o efeito localização geográfica (ELG), 2000 a 2006

\begin{tabular}{cccccccccc}
\hline & Brasil & MG & SP & PR & SC & RS & MS & MT & GO \\
\hline $\mathbf{2 0 0 0}$ & 100,00 & 100,00 & 100,00 & 100,00 & 100,00 & 100,00 & 100,00 & 100,00 & 100,00 \\
$\mathbf{2 0 0 1}$ & 101,18 & 104,42 & 96,64 & 100,55 & 105,17 & 94,41 & 101,06 & 105,59 & 110,86 \\
$\mathbf{2 0 0 2}$ & 101,79 & 105,46 & 95,29 & 99,36 & 104,08 & 95,98 & 103,34 & 118,33 & 260,38 \\
$\mathbf{2 0 0 3}$ & 102,83 & 106,49 & 81,91 & 101,28 & 104,39 & 97,83 & 103,81 & 130,54 & 391,60 \\
$\mathbf{2 0 0 4}$ & 104,43 & 110,32 & 77,54 & 105,00 & 108,71 & 93,23 & 103,93 & 168,16 & 343,37 \\
$\mathbf{2 0 0 5}$ & 106,72 & 118,01 & 73,78 & 98,94 & 116,73 & 93,89 & 103,74 & 169,69 & 295,74 \\
$\mathbf{2 0 0 6}$ & 107,04 & 120,69 & 42,72 & 96,02 & 118,34 & 100,33 & 104,04 & 177,62 & 300,07 \\
\hline
\end{tabular}

Fonte: Dados da pesquisa.

Com base nos índices da simulação da produção total (Tabela 4), verificase que o os estados de Paraná, Minas Gerais e São Paulo apresentaram significativa redução (de 7,61\%,6,79\% e 6,26\%, respectivamente). $\mathrm{Na}$ produção inspecionada (Tabela 5), o efeito localização geográfica foi crescente em Mato Grosso do Sul, Santa Catarina, Minas Gerais, Mato Grosso e, principalmente, Goiás; São Paulo foi o estado que mais perdeu posição.

Esses resultados confirmam as evidências apontadas para uma nova geografia do setor, na qual se verifica um deslocamento das empresas suinícolas para o cerrado, baseado na proximidade com as áreas fornecedoras de matérias-primas a baixo custo, especialmente milho e soja, que são importantes insumos. Essa tendência de redistribuição espacial da produção também foi observada, no estudo de Igreja et al. (2006), para a pecuária bovina. No referido estudo, a região CentroOeste igualmente revela uma parcela significativa e crescente da produção inspecionada.

Os fatores determinantes do aumento da produção inspecionada em determinados estados podem estar associados à utilização de tecnologias mais avançadas e à atuação eficiente dos agentes de fiscalização, fatores decorrentes da inserção privilegiada assumida pelas indústrias de carnes (IGREJA et al.,2006). Nesse contexto, salienta-se que o emprego de tecnologia e a atuação dos órgãos competentes responsáveis pela 
Gislene Zinato Rodrigues, Marília F. Maciel Gomes,

Denis Antônio da Cunha \& Vladimir Faria dos Santos

fiscalização da cadeia produtiva de suínos no Brasil não foram uniformes nos principais estados produtores.

De acordo com Saboya (2001), a expansão da atividade na região CentroOeste certamente continuará a aumentar, motivada pela abundante oferta de milho e soja, mas certamente sem abalar, no curto e médio prazo, a liderança da cadeia produtiva estabelecida no Sul, região tradicional na atividade. Além das matérias-primas, considerados fatores locacionais específicos, outros aspectos relativos à localização também são relevantes, como o custo de transporte dos insumos e dos produtos, a questão ambiental, o custo da mão-de-obra, os benefícios fiscais concedidos pelos estados, entre outros.

\section{Conclusões}

Os resultados obtidos neste estudo permitem concluir que a pecuária suinícola do Brasil apresentou importantes transformações. Embora a produção total de carne suína tenha apresentado crescimento significativo, a produção inspecionada mostrou dinamismo superior. As exigências do mercado externo e interno com a qualidade do alimento consumido e de acordo com aos padrões de segurança alimentar são fatores importantes para o aumento da produção inspecionada.

O maior crescimento da produção inspecionada, comparativamente à produção total, indica que a atividade suinícola apresentou melhoria tanto nas técnicas de produção (adoção de novas tecnologias) quanto na implementação de um processo de fiscalização sanitária mais eficiente.

Paralelamente, pode-se falar em um deslocamento espacial da produção. Os estados de Goiás e Mato Grosso apresentaram maiores índices de produção inspecionada e produção total, quando se levou em consideração o efeito localização geográfica, o que vem a confirmar essa nova tendência geográfica da produção, ou seja, a busca de proximidades de áreas fornecedoras de matérias-primas. 
Regiões tradicionais de produção suína, como Sul e Sudeste, apesar de terem apresentado maior concentração na produção inspecionada, mostraram menor convergência desta em relação à produção total, quando se considerou apenas o componente localização geográfica. $\mathrm{O}$ resultado é uma dinâmica de modernização nas regiões de fronteira agrícola, tendência que já havia sido verificada na pecuária bovina.

Por fim, destaca-se que as políticas públicas devem atentar para a necessidade de programas de fiscalização sanitária mais eficientes (na produção, abate, transporte e comercialização) e investimentos em infraestrutura (pessoal técnico, vacinação, pesquisas, rastreabilidade), os quais são imprescindíveis para a conquista de novos mercados e para o fortalecimento do produto nacional.

\section{Referências}

ANDRADE, W.S.P. Localização das agroindústrias de aves e suínos no Brasil. Viçosa, MG: UFV, 2005157 p. Tese (Doutorado em Economia Aplicada) - Universidade Federal de Viçosa.

ASSOCIAÇÃO BRASILEIRA DA INDÚSTRIA PRODUTORA E EXPORTADORA DE CARNE SUÍNA - Abipecs. Disponível em: $<$ http://www.abcs.com.br>. Acesso em 21/03/2007.

ASSOCIAÇÃO_BRASILEIRA DOS CRIADORES DE SUÍNOS ABCS.Disponível em: <http://www.abipecs.org.br>. Acesso em 02/04/ 2007.

CURTIS, W. C. Shift-share analysis as a tecniques in rural development research. American Journal of Agricultural Economics, v. 54, n. 2, p. 267-270, 1972.

DAGUER, R. F. J. Crescimento extensivo versus modernização da agricultura brasileira. Viçosa, MG: UFV, 1984. 83p. Dissertação (Mestrado em Economia Rural) - Universidade Federal de Viçosa. 
Gislene Zinato Rodrigues, Marília F. Maciel Gomes,

Denis Antônio da Cunha \& Vladimir Faria dos Santos

EMBRAPA SUÍNOS_E AVES. Disponível em: < http://http:// www.embrapa.br>. Acesso em 08/04/2007.

FIALHO, R. Competitividade das exportações brasileiras de carne suína, no período de 1990 a 2004. Viçosa, MG: UFV 2004. 94 p. Dissertação (Mestrado em Economia Aplicada) - Universidade Federal de Viçosa.

FNP CONSULTORIA \& COMÉRCIO. Anualpec. São Paulo: Editora Argos Comunicação, 2007.

GOMES, M. F. M. As cadeias agroindustriais da carne. In: BDMG (Org.). Minas Gerais do século XXI,v. 4. Belo Horizonte: BDMG, 2002. p. 129-183.

HADDAD, P. R. \& ANDRADE, T. Método de análise diferencialestrutural. In: HADDAD, P. R. (Org.). Economia regional: teorias e métodos de análise. Fortaleza: BNB/ETENE, 1989. p. 249-286.

HAYAMI. Y., RUTTAN, V. W. Desenvolvimento agrícola: teoria e experiências internacionais. Brasília: Embrapa, 1988. 583 p.

IGREJA, A. C. M. BLISKA, F. M. M.; FILGUEIRAS, G. C.; MARTINS, S. S.; TIRADO, G. Fator locacional na produção brasileira de carne bovina: uma análise comparada utilizando estatísticas de produção inspecionada versus produção total. Revista de Economia Agrícola, v. 53, n. 1, p. 63-80, 2006.

INSTITUTO BRASILEIRO DE GEOGRAFIA E ESTATÍSTICA IBGE. Disponível em: <http://www.sidra.ibge.gov.br>. Acesso em 05/ 03/2007

MOREIRA, C. G. Fontes de crescimento das principais culturas do Rio Grande do Norte, 1981-92. Piracicaba, SP: ESALQ, 1996, 109 p. Dissertação (Mestrado em Economia Aplicada) - Escola Superior de Agricultura Luiz Queiroz, Universidade de São Paulo. 
OLIVEIRA, A. A. S.; GOMES, M. F. M.; RUFINO, J. S. L.; SILVA JUNIOR, A. G.; GOMES, S. T. Estrutura e dinâmica da cafeicultura em Minas Gerais. Revista de Economia, v. 34, n. 1, p. 121-142, 2008.

RODRIGUES, R. O agronegócio brasileiro é um caso de sucesso. Revista de Política Agrícola, v. 15, n. 1, p. 3-4, 2006.

ROSADO, P. L. Integração espacial entre os mercados brasileiros de suínos. Viçosa, MG: UFV, 2006, 117 p. Tese (Doutorado em Economia Aplicada) - Universidade Federal de Viçosa.

SABOYA, L. V. A dinâmica locacional da avicultura e suinocultura no Centro-Oeste Brasileiro. Piracicaba, SP: ESALQ, 146 p. Dissertação (Mestrado em Economia Aplicada) - Escola Superior de Agricultura Luiz Queiroz, Universidade de São Paulo.

SALLES FILHO, S. L. M. Mudanças no padrão tecnológico da agricultura: uma perspectiva para o final do século. In: 31 . Congresso Brasileiro de Economia e Sociologia Rural, Ilhéus, 1993. Anais... Brasília: Sober, 1993.

SALLES FILHO, S. L. M., SILVEIRA, J. M. F. J. da. A teoria da inovação induzida e os modelos de "demand pull": uma crítica com base no enfoque neoschumpeteriano. In: 28. Congresso Brasileiro de Economia e Sociologia Rural, Florianópolis, 1990. Anais... Brasília: Sober, 1990.

SANTOS, F. A. et al. (2000). Fatores associados à mudança da composição agrícola em duas regiões agrícolas em Minas Gerais. In: 38. Congresso Brasileiro de Economia e Sociologia Rural, Rio de Janeiro, 2000. Anais... Brasília: Sober, 2000.

SCHUH, G. E. O desenvolvimento da agricultura no Brasil. Rio de Janeiro: Apec, 1971.369 p. 
Gislene Zinato Rodrigues, Marília F. Maciel Gomes,

Denis Antônio da Cunha \& Vladimir Faria dos Santos

SHIKIDA, P. F. A.; LOPES, A. A. O. A questão da mudança tecnológica e o enfoque neoclássico. Teoria e Evidência Econômica, v. 5, n. 9, p.79-90, 1997.

SILVA, C. R. L. Inovação tecnológica na agricultura brasileira: aspectos distributivos. São Paulo, SP: USP/FEA, 1992. 216p. Tese (Doutorado em Economia).Universidade de São Paulo.

Abstract: The objective of this paper is to analyze the production shares of the main Brazilian states (Minas Gerais, São Paulo, Paraná, Santa Catarina, Rio Grande do Sul, Mato Grosso do Sul, Mato Grosso and Goiás) in the national production of inspected and total pork meat in the period from 2000 to 2006. The analysis considered the evolution of the production in terms of the regional effects, and indicators of the technical evolution of the production. The theoretical model used is the induced innovation model, based on agricultural modernization theory. The analysis method was the shift-share model. The results showed that the pork Brazilian production presented important transformations. Although the total production of pork meat has presented significant growth, the inspected production showed superior dynamism. The production is moving to regions closed to raw material supplying areas. The result is a production modernization dynamics in the areas of agricultural border, trend that had already been verified in the bovine livestock.

Keywords: local factor, technological factor, Shit-Share Model, pork meat. 


\section{Anexo}

Tabela $1 \mathrm{~A}$ - Índices da quantidade total produzida de carne suína, Brasil e principais estados produtores, 2000 a 2006

\begin{tabular}{ccccccccccc}
\hline & Brasil & MG & SP & PR & SC & RS & MS & MT & GO & Outros \\
\hline $\mathbf{2 0 0 0}$ & 100,00 & 100,00 & 100,00 & 100,00 & 100,00 & 100,00 & 100,00 & 100,00 & 100,00 & 100,00 \\
$\mathbf{2 0 0 1}$ & 102,56 & 105,73 & 99,42 & 103,03 & 103,52 & 100,91 & 104,52 & 111,99 & 104,71 & 101,03 \\
$\mathbf{2 0 0 2}$ & 105,19 & 111,79 & 98,85 & 106,15 & 107,16 & 101,82 & 109,23 & 125,43 & 109,65 & 101,91 \\
$\mathbf{2 0 0 3}$ & 108,82 & 124,93 & 97,74 & 107,44 & 108,72 & 107,20 & 120,37 & 144,25 & 125,57 & 101,71 \\
$\mathbf{2 0 0 4}$ & 113,29 & 130,99 & 97,13 & 115,81 & 118,50 & 104,57 & 124,02 & 170,25 & 125,14 & 104,03 \\
$\mathbf{2 0 0 5}$ & 116,64 & 138,77 & 97,61 & 116,21 & 131,01 & 108,14 & 126,55 & 180,45 & 130,35 & 102,16 \\
$\mathbf{2 0 0 6}$ & 118,97 & 143,36 & 84,92 & 113,64 & 135,24 & 112,91 & 129,43 & 188,16 & 131,65 & 106,37 \\
\hline
\end{tabular}

Fonte: Elaborada a partir de dados do Anualpec (2007).

Tabela 2A -Índices da produção inspecionada de carne suína, Brasil e principais estados produtores, 2000 a 2006

\begin{tabular}{ccccccccccc}
\hline & Brasil & MG & SP & PR & SC & RS & MS & MT & GO & Outros \\
\hline $\mathbf{2 0 0 0}$ & 100,00 & 100,00 & 100,00 & 100,00 & 100,00 & 100,00 & 100,00 & 100,00 & 100,00 & 100,00 \\
$\mathbf{2 0 0 1}$ & 117,54 & 131,95 & 103,95 & 111,96 & 111,95 & 117,77 & 120,49 & 71,40 & 746,39 & 115,98 \\
$\mathbf{2 0 0 2}$ & 139,64 & 155,12 & 136,99 & 141,92 & 123,77 & 136,19 & 143,70 & 110,82 & 1304,30 & 130,22 \\
$\mathbf{2 0 0 3}$ & 142,33 & 162,11 & 144,42 & 152,62 & 123,54 & 129,06 & 121,33 & 202,30 & 1613,59 & 113,98 \\
$\mathbf{2 0 0 4}$ & 138,65 & 164,44 & 143,59 & 144,76 & 117,45 & 124,46 & 99,90 & 285,14 & 1744,29 & 114,17 \\
$\mathbf{2 0 0 5}$ & 160,10 & 190,99 & 153,25 & 156,29 & 140,16 & 148,94 & 104,87 & 381,62 & 1831,99 & 138,50 \\
$\mathbf{2 0 0 6}$ & 170,74 & 216,11 & 196,73 & 165,90 & 130,80 & 183,29 & 111,21 & 362,00 & 1740,54 & 194,11 \\
\hline
\end{tabular}

Fonte: Elaborada a partir de dados básicos do IBGE (2007). 
Gislene Zinato Rodrigues, Marília F. Maciel Gomes,

Denis Antônio da Cunha \& Vladimir Faria dos Santos

Tabela 3A-Simulação da Quantidade Total Produzida de suínos, Brasil, em mil toneladas, a partir do Modelo Shift-Share, 2000 a 2006

\begin{tabular}{cccccc}
\hline Ano & EDR $^{1}$ & EPM $^{2}$ & ETD $^{3}$ & ELG $^{4}$ & Produção \\
\hline $\mathbf{2 0 0 0}$ & $2.336,392$ & $2.336,392$ & $2.336,392$ & $2.336,392$ & $2.336,392$ \\
$\mathbf{2 0 0 1}$ & $2.284,361$ & $2.352,034$ & $2.570,253$ & $2.336,108$ & $2.396,300$ \\
$\mathbf{2 0 0 2}$ & $2.224,165$ & $2.371,264$ & $2.894,985$ & $2.337,138$ & $2.457,743$ \\
$\mathbf{2 0 0 3}$ & $2.076,450$ & $2.400,617$ & $3.054,153$ & $2.345,238$ & $2.542,396$ \\
$\mathbf{2 0 0 4}$ & $1.999,687$ & $2.426,078$ & $3.068,143$ & $2.334,358$ & $2.646,823$ \\
$\mathbf{2 0 0 5}$ & $2.058,748$ & $2.440,962$ & $3.121,286$ & $2.370,916$ & $2.725,114$ \\
$\mathbf{2 0 0 6}$ & $2.189,320$ & $2.444,415$ & $3.126,299$ & $2.380,259$ & $2.779,692$ \\
\hline
\end{tabular}

${ }^{1}$ Efeito dimensão do rebanho; ${ }^{2}$ Efeito peso médio das carcaças; ${ }^{3}$ Efeito taxa de desfrute; ${ }^{4}$ Efeito localização geográfica.

Fonte: Dados da pesquisa.

Tabela 4A - Simulação da Produção Inspecionada de suínos, em mil toneladas, a partir do Modelo Shift-Share, Brasil, 2000 a 2006

\begin{tabular}{cccccc}
\hline Ano & EDR $^{1}$ & EPM $^{2}$ & ETD $^{3}$ & ELG $^{4}$ & Produção \\
\hline $\mathbf{2 0 0 0}$ & $1.346,073$ & $1.346,073$ & $1.346,073$ & $1.346,073$ & $1.346,073$ \\
$\mathbf{2 0 0 1}$ & $1.389,369$ & $1.380,495$ & $1.482,881$ & $1.361,890$ & $1.582,133$ \\
$\mathbf{2 0 0 2}$ & $1.356,940$ & $1.389,086$ & $1.793,137$ & $1.370,218$ & $1.879,653$ \\
$\mathbf{2 0 0 3}$ & $1.379,143$ & $1.396,617$ & $1.794,420$ & $1.384,149$ & $1.915,856$ \\
$\mathbf{2 0 0 4}$ & $1.424,563$ & $1.425,883$ & $1.654,875$ & $1.405,660$ & $1.866,374$ \\
$\mathbf{2 0 0 5}$ & $1.478,896$ & $1.553,012$ & $1.733,945$ & $1.436,527$ & $2.155,016$ \\
$\mathbf{2 0 0 6}$ & $1.494,719$ & $1.546,017$ & $1.891,128$ & $1.440,873$ & $2.298,241$ \\
\hline
\end{tabular}

${ }^{1}$ Efeito dimensão do rebanho; ${ }^{2}$ Efeito peso médio das carcaças; ${ }^{3}$ Efeito taxa de desfrute; ${ }^{4}$ Efeito localização geográfica.

Fonte: Dados da pesquisa. 
REVISTA DE ECONOMIA E AGRONEGÓCIO, VOL.6, $N^{o} 3$ 